PRACTITIONERS SECTION

\title{
PAMIDRONATE - A PROMISING NEW CANDIDATE FOR THE MANAGEMENT OF SPONDYLOARTHROPATHY
}

\author{
S. M. AKERKAR, L. S. BICHILE
}

\section{ABSTRACT}

Bisphosphonate group of agents are known for their anti-bone resorptive properties. However, recently their anti-inflammatory and anti-arthritis properties have come to light. Clinical trials of their use in spondyloarthropathy are showing promising results, especially in patients with shorter disease duration. The adverse event profile is mainly limited to postinfusion arthralgia, myalgia and fever. The concept of pamidronate in spondyloarthropathy management should be evaluated further in light of these clinical studies and could have a major impact on our resource-restricted setting.

KEY WORDS: Pamidronate, Bisphosphonates, Ankylosing spondylitis, spondyloarthropathy

Ankylosing spondylitis (AS) is a frequently occurring chronic disease. For the past several decades, NSAIDs and physiotherapy have been the mainstay of therapy. Most NSAIDs, including the COX-2 inhibitors, are of symptomatic benefit with no disease modifying properties. Sulfasalazine has been evaluated in several trials; however, the results are not consistent. Biological agents have been a major breakthrough in the management of the disease. However, in a country like India these agents will be of limited use in view of the high costs. Hence, the concept of bisphosphonte therapy in AS is worth pursuing in view of its promising reports in western countries.

Department of Medicine, Seth GS and KEM Hospital Parel, Mumbai, India

Correspondence:

\section{HISTORY OF BISPHOSPHONATES}

Bisphosphonates are pyrophosphate analogues and have been known to the chemists since the 19th century; the first synthesis dating back to $1865 .^{[1]}$ They were used in industry, mainly as corrosion inhibitors. They were known to inhibit calcium carbonate precipitation and this property led to their use in scaling. ${ }^{[2]}$ This unique property was later studied both in vitro and in vivo. These studies revealed their effect on mineralization and bone resorption. ${ }^{[3,4]}$ They were also found to inhibit ectopic calcification in vivo and this led to the hypothesis that local pyrophosphatases

S. M. Akerkar, Rheumatology Division, Department of Medicine, Se,h GS and KEM Hospital, Parel, Mumbai - 400 012, India. E-mail: shashank77_2000@yahoo.com could be physiological regulators of calcification and perhaps also of decalcification. ${ }^{[5]}$

\section{CHEMICAL STRUCTURE}

Bisphosphonates are compounds characterized by two C-P bonds. The P-C-P group is resistant to enzymatic hydrolysis and hence they are not metabolized in the body and excreted unaltered. The P-C-P structure allows a great number of possible variations, mostly by changing the two lateral chains on the carbon. Small changes in the structure of the bisphosphonates can lead to extensive alterations in their physicochemical, biological, therapeutic and toxicological characteristics.

\section{ANTI-ARTHRITIC AND ANTI- INFLAMMATORY EFFECTS}

Bisphosphonates have been evaluated in various animal models of arthritis: rat adjuvantinduced polyarthritis, murine-antigen-induced arthritis and a murine model of chronic inflammation; the delayed type hypersensitivity granuloma reaction. They were found to inhibit the chronic inflammatory response associated with delayed type hypersensitivity and erosive arthritis in these animal models. ${ }^{[6-9]}$ Recent work into their mechanism of action has shown that they specifically inhibit the enzyme farnesyl diphosphate synthetase in the mevalonate pathway. ${ }^{[10]}$ This leads to impaired prenylation of a number of proteins that are involved in inflammatory cascade like the Ras superfamily. ${ }^{[11]}$ Effect has also been noted on cells of the monocyte/macrophage lineage with inhibition of growth, migration, differentiation and viability. ${ }^{[12,13]}$ Exposure of the cultured macrophages to Pamidronate has been shown to suppress the generation of pro inflammatory cytokines including TNF- $\alpha .{ }^{[14]}$ This is a dosedependent phenomenon occurring at a concentraion of $10^{-5} \mathrm{M}$. Although these levels are unlikely to be attained by IV Pamidronate in blood, the levels of Pamidronate in the vicinity of resorbing bone are much higher; up to $10^{-3} .{ }^{[15]}$ Alendronate has been shown to impair the antigen presenting function of the peripheral blood monocytes. ${ }^{[16]}$ Pamidronate has also been shown to retard structural damage in a TNF- $\alpha$ transgenic mouse model. ${ }^{[17]}$

The anti-resorptive properties can also be explained on the basis of the prenylation theory as this affects a number of proteins that ultimately leads to apoptosis of the

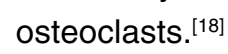

The evaluation of pamidronate in ankylosing arthritis was prompted by the observation that bisphosphonates reduce chronic inflammation and pathological mineralization in animal models of arthritis. ${ }^{[19,20]}$

\section{TRIALS OF PAMIDRONATE IN SPONDYLOARTHROPATHY}

In Edmonton, anti-inflammatory properties of pamidronate were evaluated in 16 patients with NSAID refractory active AS. ${ }^{[21]}$ Sixteen patients with mean disease duration of 12.3 years were randomized to two equal groups. One group received six infusions per month; $30 \mathrm{mg}$ for the first 3 months and $60 \mathrm{mg}$ for the next 3 months while the other group received $60 \mathrm{~g}$ per month for 3 months only. An amount of $30-60 \mathrm{mg}$ dose was used in view of the previous 
experience with this dose in Paget's disease and osteoporosis. Clinical outcome measures included the BASDAI for measurement of disease severity, BASFI for measurement of functional impairment, and BASMI for measurement of spinal mobility. Group 1 showed significant improvements in BASDAl and BASMI scores ( $P<0.03$ for both) and in the ESR $(P=0.009)$. Group 2 showed a significant improvement only in the BASMI $(P=0.007)$, with no significant change in BASDAl score or ESR. Five out of the seven patients of group 1 had reductions of the BASDAI score of more than $30 \%$ and it persisted for at least 3 months posttreatment. Maximum change in clinical parameters and ESR was observed in the 3-6 month period. Thus, the trial indicated delayed but long lasting and significant effects of pamidronate in NSAID refractory AS.

A second preliminary open study ${ }^{[2]}$ assessed an intensive regime of Pamidronate $(60 \mathrm{mg}$ pamidronate at 1, 2, 14, 28 and 56 days). Nine patients with NSAID refractory peripheral SpA (5-AS, 3-undifferentiated SpA and 1-reactive arthritis) with mean disease duration of 5.5 years were included. Patients were assessed up to 84 days. The study found significant improvement in all clinical and laboratory parameters. The mean BASDAI decreased by $44.2 \%$ ( $P=0.028)$, mean BASFI by $47 \%(P=0.015)$, mean BASGI by $42 \%$ $(P=0.011)$, mean ESR by $49.4 \%$ and CRP by $66.9 \%$. Additional benefit was also seen in peripheral joints with a decrease in mean tender and swollen joint count by $98.2 \%$ $(P=0.012)$ and $93.8 \%(P=0.017)$, respectively. Dynamic MR imaging with Gadolinium enhancement was also carried out in these patients at baseline and at posttreatment. Maximal rate and magnitude of the MR signal after Gadolinium enhancement was found to decrease in these patients thus implying the effect on bone marrow edema.

A placebo-controlled trial of pamidronate is no feasible due to the high incidence of posttransfusion (after the first dose) arthralgias and myalgias; thus compromising blinding. An amount of $10 \mathrm{mg}$ dose is the lowest dose of IV pamidronate that has been shown to induce postinfusion arthralgias and myalgias. Hence a randomized, double blind trial[23] comparing $60 \mathrm{mg}$ vs $10 \mathrm{mg}$ IV pamidronate was conducted. This was also the biggest trial with 84 NSAID refractory AS patients. Seventy-two completed the 6 months therapy. Significant changes in BASFI, BASDAI and BASGI was evident at 6 months (the same were found to be insignificant at 3 months). At 6 months, the mean BASDAI had decreased by 2.22 (34.5\%) in the $60 \mathrm{mg}$ group and by $0.93(15 \%)$ in the $10 \mathrm{mg}$ group. Significantly greater reductions in the $60 \mathrm{mg}$ group were also noted for the BASFI $(P<0.01)$, BASGI $(P=0.01)$ and BASM $(P=0.03)$. Significantly more patients achieved a reduction of $>25 \%$ in the BASDAl in the $60 \mathrm{mg}$ group vs the $10 \mathrm{mg}$ group $(63.4 \%$ vs $30.2 \% ; P=0.004$ )

An open observational study with 12 active AS patients with mean disease duration of 20 years by Haibel et al. ${ }^{[2]}$ found a significant reduction in the BASDAI $(P=0.04)$, physician and patient global assessment at 3 months. An ASAS $20 \%$ response was seen in 2 of 11 patients at the end of 3 months and four of nine patients at the end of 6 months.
Cairns et al. ${ }^{[25]}$ evaluated the bone markers in patients with AS on Pamidronate. Six infusions per month were given; $30 \mathrm{mg}$ being the starting dose followed by $60 \mathrm{mg}$. Fifteen patients with mean disease duration of 14.8 years participated in the study. The study revealed a significant fall in degradation products of typeI collagen C-terminal telopeptides $(P=0.001)$, Serum bone GLA protein $(P=0.02)$, bonespecific alkaline phosphatase $(P=0.02)$. Significant improvement was seen in the BASDAI score; but not in BASMI, CRP or ESR.

\section{ADVERSE EVENT PROFILE}

Most common adverse event reported after IV pamidronate is flu-like syndrome with fever spike, arthralgias and myalgia. These are largely limited to the first infusion. Another study reported transient arthralgias/myalgias after the first infusion in $68.3 \%$ patients. ${ }^{[23]}$ The adverse events are independent of the dose and are seen irrespective of whether the first dose is 30 or $60 \mathrm{mg} \cdot{ }^{[26]}$ Prolonged hypocalcaemia is a known but a rare complication of pamidronate infusion. ${ }^{[27]}$

\section{CONCLUSIONS}

Pamidronate seems to be a potential agent in the management of spondyloarthropathy. This should be viewed in light of the fact that there are very few options in the management of spondyloarthropathies; with TNF- $\alpha$ inhibitors being out of reach of a majority of the population. The disease duration at the start of therapy does seem to affect the outcome of therapy. Postinfusion myalgia, arthralgia, and fever are the commonest adverse effects and are independent of the dose of first infusion.
Although disease activity shows an early improvement, a significant improvement in inflammatory markers lags behind the clinica response. Clinical trials with a longer duration should provide significant inputs towards further clinical use of this agent.

\section{REFERENCES}

1. Menschutkin N. Ueber die Einwirkung des Chlorazetyls auf phosphorige Säure. Ann Chem Pharm 1865;133:317-20.

2. Blomen LJMJ. History of the bisphosphonates: discovery and history of the non-medical uses of bisphosphonates. In: Bijvoet OLM, Fleisch HA, Canfield RE, Russell RGG, editors. Bisphosponate on bones. Amsterdam: Elsevier; 1995. p. 111-24.

3. Fleisch $H$, Russell RGG, Francis MD Diphosphonates inhibit hydroxyapatite dissolution in vitro and bone resorption in tissue culture and in vivo. Science (Wash, DC) 1969;165:1262-4

4. Francis MD, Russell RGG, Fleisch $H$ Diphosphonates inhibit formation of calcium phosphate crystals in vitro and pathological calcification in vivo. Science (Wash, DC) 1969;165:1264-6.

5. Fleisch H, Russell RGG, Straumann F. Effect of pyrophosphate on hydroxyapatite and its implications in calcium homeostasis. Nature 1966;212:901-3.

6. Dunn CJ, Galinet LA, Wu H, Nugent RA Schlachter ST, Staite ND, et al. Demonstration of novel anti-arthritic and anti-inflammatory effects of diphosphonates. J Pharmacol Exp Ther 1993;266:1691-8.

7. Nugent RA, Schlachter ST, Murphy M, Dunn CJ, Staite ND, Galinet LA, et al. Carbonyl-containing bisphosphonate esters as novel antiinflammatory and antiarthritic agents. J Med Chem 1994;37:4449-54. 
8. Schlachter ST, Galinet LA, Shields SK, Aspar DG, Dunn CJ, Staite ND, et al. Anti-inflammatory/ antiarthritic ketonic bisphosphonic acid esters. Bioorg Med Chem Lett 1998;8:1093-6.

9. Nugent RA, Murphy M, Schlachter ST, Dunn CJ, Smith RJ, Staite ND, et al. Pyrazoline bisphosphonate esters as novel antiinflammatory and antiarthritic agents. J Med Chem 1993:36:134-9.

10. Van Beek E, Pieterman E, Cohen L, Lowik C, Papapoulos S. Farnesyl pyrophosphate synthase is the molecular target of nitrogen-containing bisphosphonates. Biochem Biophys Res Commun 1999;264:108-11.

11. Khwaja A, Conolly J, Hendry B. Prenylation inhibitors in renal disease. Lancet 2000;355: 741-4.

12. Cecchini MG, Fleisch $H$. Bisphosphonates in vitro specifically inhibit, among the hematopoietic series, the development of the mouse mononuclear phagocyte lineage. J Bone Miner Res 1990;5:1019-27.

13. Stevenson PH, Stevenson JR. Cytotoxic and migration inhibitory effects of bisphosphonates on macrophages. Calcif Tissue Int 1986;38: 227-33.

14. Pennanen N, Lapinjoki S, Urti A, Monkkonen J. Effect of liposomal and free bisphosphonates on the IL-10, IL-6 and TNF alpha secretion from RAW 264 cells in vitro. Pharm Res 1995;12: 916-22.

15. Sato M, Graser W. Effects of bisphosphonates on isolated rat osteoclasts as examined by reflected light microscopy. J Bone Miner Res 1990;5:31-40.

16. Sansoni P, Passeri G, Fagnoni F, Mohagheghpour N, Snelli G, Brianti V, et al. Inhibition of antigen-presenting cell function by alendronate in vitro. J Bone Miner Res 1995;10:1719-25.

17. Redlich K, Hayer S, Maier A, et al. Tumor necrosis factor a-mediated joint destruction is inhibited by targeting osteoclasts with osteoprotegerin.
Arthritis Rheum 2002;46:785-92.

18. Luckman SP, Hughes DE, Coxon FP, Russell G, Rogers MJ. Nitrogen-containing bisphosphonates inhibit the mevalonate pathway and prevent post-translational prenylation of GTP-binding proteins, including Ras. J Bone Miner Res 1998;13:581-9.

19. Francis MD, Hovancik K, Boyce RW. NE-58095: a diphosphonate which prevents bone erosion and preserves joint architecture in experimental arthritis. Int J Tissue React 1989;11:239-52.

20. Flora L. Comparative antiinflammatory and bone protective effects of two diphosphonates in adjuvant arthritis. Arthritis Rheum 1979;22:340-6.

21. Maksymowych WP, Jhangri GS, Leclercq $S$, Skeith $K$, Yan A, Russell AS. An open study of pamidronate in the treatment of refractory ankylosing spondylitis. J Rheumatol 1998;25:714-7.

22. Maksymowych WP, Lambert R, Jhangri GS Leclercq S, Chiu P, Wong B, et al. Clinical and radiological amelioration of refractory periphera spondyloarthritis by pulse intravenous pamidronate therapy. J Rheumatol 2001;28:14455.

23. Maksymowych WP, Jhangri GS, Fitzgerald AA. A six-month randomized, controlled, double-blind, dose-response comparison of intravenous pamidronate $(60 \mathrm{mg}$ versus $10 \mathrm{mg}$ ) in the treatment of nonsteroidal antiinflammatory drugrefractory ankylosing spondylitis. Arthritis Rheum 2002;46:766-73.

24. Haibel H, Brandt J, Rudwaleit M, Soerensen $\mathrm{H}$ Sieper J, Braun J. Treatment of active ankylosing spondylitis with pamidronate. Rheumatology 2003;42:1018-20.

25. Cairns AP, Wright SA, Taggart AJ, et al. An open study of pulse pamidronate treatment in severe ankylosing spondylitis, and its effect on biochemical markers of bone turnover. Ann Rheum Dis 2005;64:338-9.

26. Buckler HM, Mercer SJ, Davison CE, et al. Evaluation of adverse experiences related to pamidronate infusion in Paget's disease of bone. Ann Rheum Dis 1998;57:572.

27. Singh R, Menon Y, Cuchacovich R, et al. A sixmonth randomized, controlled, double-blind, dose-response comparison of intravenous pamidronate (60 $\mathrm{mg}$ versus $10 \mathrm{mg}$ ) in the treatment of nonsteroidal antiinflammatory drugrefractory ankylosing spondylitis: comment on the article by Maksymowych et al. Arthritis Rheum 2003;48:583-4 